\title{
The duration of the Bølling-Allerød period (Greenland Interstadial 1) in the GRIP ice core
}

\author{
Inger K. SEIERSTAD, ${ }^{1}$ Sigfús J. JOHNSEN, ${ }^{1}$ Bo M. VINTHER, ${ }^{1}$ Jesper OLSEN ${ }^{2}$ \\ ${ }^{1}$ Department of Geophysics, University of Copenhagen, Juliane Maries Vej 30, DK-2100 Copenhagen, Denmark \\ E-mail: inger@gfy.ku.dk \\ ${ }^{2}$ Department of Physics and Astronomy, University of Arhus, Ny Munkegade, DK-8000 Århus, Denmark
}

\begin{abstract}
A new dating of the Bølling-Allerød period (Greenland Interstadial event 1) in the GRIP ice core is presented. Newly measured profiles of $\delta \mathrm{D}$ and $\delta^{18} \mathrm{O}$, as well as existing profiles of $\mathrm{Ca}^{2+}, \mathrm{NH}_{4}{ }^{+}$, dust and $\mathrm{NO}_{3}{ }^{-}$, have been used for the dating. As seasonal variations can be observed in all six components, it was possible to simultaneously count annual layers in the profiles in order to obtain a multi-parameter dating. The new data presented in this study include a total of $36.85 \mathrm{~m}$ of stable-isotope profiles of $1 \mathrm{~cm}$ resolution from five sections of the Bølling-Allerød period in the GRIP ice core. The annual-layer counting suggests a duration of the complete Bølling-Allerød period, as revealed in the GRIP ice core, of $1627 \pm 52$ years. This estimate contrasts with an earlier finding from the same GRIP ice core, where the Bølling-Allerød was found to span 2168 years (Hammer, in press). This estimate was based on layer counting, using dust concentrations only.
\end{abstract}

\section{INTRODUCTION}

The $3028 \mathrm{~m}$ long GRIP (Greenland Icecore Project) ice core was drilled in 1989-92 at Summit $\left(72^{\circ} 34^{\prime} \mathrm{N} 37^{\circ} 37^{\prime} \mathrm{W}\right)$, Greenland (GRIP Members, 1993). The Bølling-Allerød period (Greenland Interstadial 1) is found more than halfway down the ice sheet, at $\sim 1700 \mathrm{~m}$ depth, where the annuallayer thickness is about $4-6 \mathrm{~cm}$.

The GRIP ice core constitutes a continuous archive of snow and ice, which gives information on past climate in Greenland back to $\sim 120000$ years BP. Precise dating of the ice core is essential to gain knowledge of climate variability through time. The stratigraphical dating of the GRIP ice core is based on annual-layer counting using $\delta^{18} \mathrm{O}, \mathrm{Ca}^{2+}$ and $\mathrm{NH}_{4}{ }^{+}$profiles back to the transition between the last glacial period and the Holocene (Fuhrer and others, 1993, 1996; Johnsen and others, 1999). For older ice, counting has been performed on seasonal variations of dust concentrations back to 60000 years BP (The Greenland Summit Ice Cores CD-ROM, 1997; Hammer, in press). Modelled timescales are available down to the Eemian (Johnsen and others, 2001).

The annual counting of dust concentrations has given estimated durations of the Bølling and Allerød of 1432 and 736 years, respectively (Hammer, in press). As dust is brought to Greenland by storms, peaks in dust are, however, likely to represent depositional events, rather than annuality. Due to this, dust may show 'double peaks' within one year. When having only this parameter for dating, there is therefore a risk of overestimating the number of years. Motivated by this fact, this study was set up to include as many independent parameters as possible in the dating, all measured in high resolution and showing seasonal variations. These parameters include $\mathrm{Ca}^{2+}$ and $\mathrm{NH}_{4}{ }^{+}$(Fuhrer and others, 1993, 1996), dust and $\mathrm{NO}_{3}{ }^{-}$ (Hammer, in press) existing for the whole period of investigation, and new sections of $\delta \mathrm{D}$ and $\delta^{18} \mathrm{O}$. The main focus has been on the stable-isotope profiles, as they are known to be ideal tools for dating ice cores under favourable conditions. They show a strong seasonal cycle, with high values during summer and low values during winter. However, diffusion of isotopes in the firn and ice leads to a smoothed isotope profile as time passes (Johnsen, 1977; Johnsen and others, 2000). Hereby the vulnerable annual cycle is weakened at greater depths. The diffusion process in the firn is dependent on temperature and annual accumulation rates. For the annual cycle to survive the densification process in Greenland, the annual accumulation rate has to be greater than $\sim 0.2 \mathrm{~m}^{\text {ice }} \mathrm{a}^{-1}$ (Johnsen, 1977). At present at the GRIP site, the accumulation rate is $\sim 0.23 \mathrm{mice}^{-1}$ and the average annual temperature is $-32{ }^{\circ} \mathrm{C}$ (Johnsen and others, 1992).

Until now, stable isotopes have not been used as a dating tool within the glacial period, partly because of low accumulation during glacial times, which speeds up the smoothing of the isotope profile, and partly because of the thin annual layers, which require a high sampling rate. The Bølling-Allerød interstadial was characterized by a warmer climate and a higher accumulation rate than during the rest of the glacial period (Johnsen and others, 1995), which is promising for retaining the annual cycle. It is hoped that this study will show whether it is feasible to use stable isotopes for dating purposes within the Bølling-Allerød interstadial.

New data presented in this study are high-resolution $(1 \mathrm{~cm}) \delta \mathrm{D}$ and $\delta^{18} \mathrm{O}$ profiles, from sections of the BøllingAllerød interstadial in the GRIP ice core. The stable-isotope series are sampled from $\sim 1700 \mathrm{~m}$ depth. There are three intervals of detailed $\delta \mathrm{D}$, covering a total of $22 \mathrm{~m}$ of ice, and two intervals of $\delta^{18} \mathrm{O}$, covering $14.85 \mathrm{~m}$ of ice (Table 1; Fig. 1). The stable-isotope profiles have been deconvoluted to correct for diffusion in the firn and ice. The aim of this study is to investigate whether it is possible to retrieve the annual signal in the isotope data from this depth of the GRIP core and, if so, to estimate the duration of the Bølling-Allerød interstadial, by counting annual cycles in these new data together with annual cycles seen in available high-resolution series of $\mathrm{Ca}^{2+}, \mathrm{NH}_{4}{ }^{+}, \mathrm{NO}_{3}{ }^{-}$and dust. 
Table 1. Depth intervals of the data from the GRIP ice core used for annual counting of the Bølling-Allerød. $L$ is the length of each data interval, $\Delta x$ is the sample interval of the data series, $\mathrm{D}$ indicates data that have been deconvoluted, and $\mathrm{H}$ data that have been highpass filtered. The column BA shows which part of the Bølling (B), Older Dryas (OD) or Allerød (A) the series covers. The depths 1753.3 and $1662.4 \mathrm{~m}$ are taken as the onset of the Bølling and the termination of the Allerød, respectively. The depth interval of the Older Dryas is defined to be $1715.0-1718.6 \mathrm{~m}$. See text for explanation

\begin{tabular}{lccccc}
\hline Data & $\begin{array}{c}\text { Depth } \\
\mathrm{m}\end{array}$ & $\begin{array}{c}L \\
\mathrm{~m}\end{array}$ & $\begin{array}{c}\Delta x \\
\mathrm{~m}\end{array}$ & $\mathrm{D} / \mathrm{H}$ & $\mathrm{BA}$ \\
& & & & & \\
\hline$\delta^{18} \mathrm{O}$ I & $1689.61-1703.35$ & 13.75 & 0.01 & $\mathrm{D}$ & Mid A \\
$\delta^{18} \mathrm{O}$ II & $1749.01-1750.10$ & 1.10 & 0.01 & $\mathrm{D}$ & Start B \\
$\delta \mathrm{D} \mathrm{I}$ & $1714.35-1719.85$ & 5.50 & 0.01 & $\mathrm{D}$ & $\mathrm{OD}$ \\
$\delta \mathrm{D} \mathrm{II}$ & $1729.20-1735.25$ & 6.05 & 0.01 & $\mathrm{D}$ & Mid B \\
$\delta \mathrm{D} \mathrm{III}$ & $1744.6-1755.05$ & 10.45 & 0.01 & $\mathrm{D}$ & Start B \\
$\mathrm{NO}_{3}{ }^{-*}$ & $1662.4-1753.3$ & 90.90 & $0.001-0.01$ & & BA \\
Dust $^{*}$ & $1662.4-1753.3$ & 90.90 & $0.001-0.01$ & & BA \\
$\mathrm{Ca}^{2+\dagger}$ & $1662.4-1753.3$ & 90.90 & 0.002 & $\mathrm{D}+\mathrm{H}$ & $\mathrm{BA}$ \\
$\mathrm{NH}_{4}{ }^{\dagger}$ & $1662.4-1753.3$ & 90.90 & 0.002 & & BA \\
\hline${ }^{*}$ & & & & &
\end{tabular}

*Hammer (in press).

Fuhrer and others $(1993,1996)$.

\section{DATA}

A total of 2200 ice samples were cut for $\delta \mathrm{D}$ measurements. The ice, which has been stored at $-26^{\circ} \mathrm{C}$, was cut in $1 \mathrm{~cm}$ pieces along the ice core, each sample constituting a total volume of $\sim 2 \mathrm{~cm}^{3}$. The relative abundance of the stable hydrogen isotopes $\left({ }^{2} \mathrm{H}\right.$ and $\left.{ }^{1} \mathrm{H}\right)$ was measured on a Micromass (now GV Instruments) continuous-flow Isotope Ratio Mass Spectrometer (CF-IRMS) (Morrison and others, 2001) configured for a chromium reduction technique, using $0.3-0.5 \mu \mathrm{L}$ of each melted sample. The isotopic ratios have been corrected for the production of ${ }^{1} \mathrm{H}_{3}{ }^{+}$ions, and the raw $\delta \mathrm{D}$ values (expressed relative to the reference gas) have been corrected for possible drift through the run and for a minor inter-sample memory effect. As a last step, the values have been expressed relative to V-SMOW (Vienna Standard Mean Ocean Water) and normalized to the V-SMOW-SLAP (Standard Light Antarctic Precipitation) scale (Coplen, 1988; IUPAC, 1994; Nelson, 2000). The average normalization constant was 1.017 .

The $\delta^{18} \mathrm{O}$ samples were cut in $1 \mathrm{~cm}$ pieces, and the volume of each sample constituted at minimum $3 \mathrm{~cm}^{3}$. The $\delta^{18} \mathrm{O}$ measurements were performed on a mass spectrometer which applies an equilibrium method, where the melted ice samples are equilibrated with $\mathrm{CO}_{2}$ gas under vibrations. The samples were kept in equilibrium with $\mathrm{CO}_{2}$ gas for 6 hours before the gas was subjected to isotopic analysis. The ratio of mass 46 and 44 is a measure of the $\mathrm{O}^{18} / \mathrm{O}^{16}$ ratio in the sample. A total of 1485 samples were measured. The sampling and the measurements of the $\delta^{18} \mathrm{O}$ data were performed by T. Ebbensgaard Strømfeldt, T. Jürgensen and A. Boas at the University of Copenhagen, Denmark.

To be able to use the annual signal in the isotope series for dating, a deconvolution technique (Figs 3 and 4) has been used to enhance the annual amplitude, which has been weakened through diffusion processes in the firn and ice (Johnsen, 1977; Johnsen and others, 2000). The diffusion
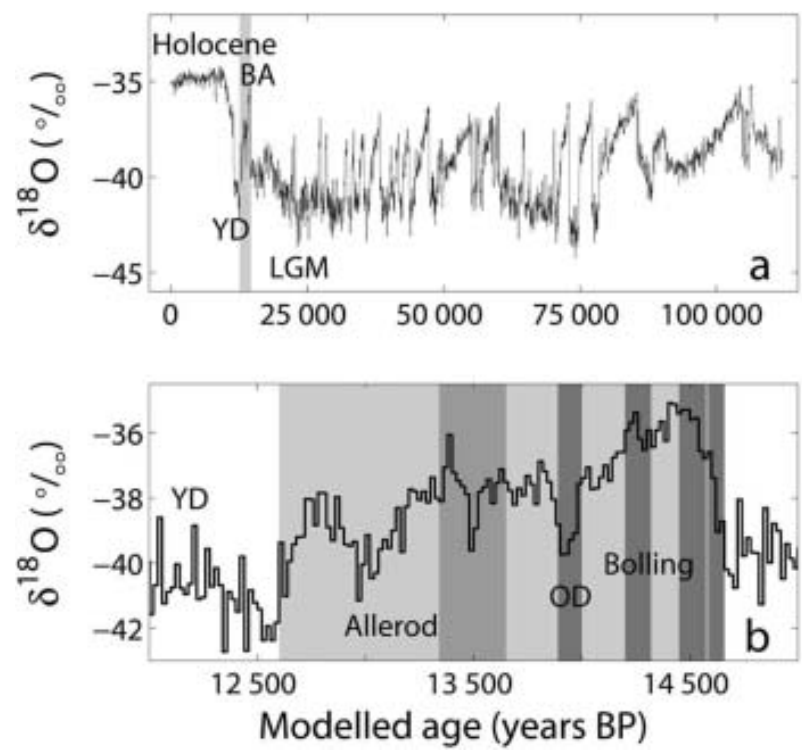

Fig. 1. $\delta^{18} \mathrm{O}$ profiles on a modelled timescale (ss09sea) (Johnsen and others, 2001). (a) 50 year averages of $\delta^{18} \mathrm{O}$. The Bølling-Allerød (BA, light-grey band) is the last interstadial (Gl event 1) before the cold Younger Dryas (YD) and the subsequent warming in the PreBoreal of the Holocene. LGM: Last Glacial Maximum. (b) Zoom of the investigated interval (coloured area): 20 year averages of $\delta^{18} \mathrm{O}$. The three dark-grey bands indicate the intervals where ice has been sampled and analyzed for $\delta \mathrm{D}$ in high resolution to retrieve annual layers and improve the dating of the climate period. The two medium dark areas show the intervals where detailed $\delta^{18} \mathrm{O}$ is included in the dating. The deepest $\delta^{18} \mathrm{O}$ series overlaps a $1.1 \mathrm{~m}$ section of the deepest $\delta \mathrm{D}$ interval. See Table 1 for the depth intervals of the stable-isotopes sections. OD: Older Dryas.

process can be mathematically described as convolving the initial (unknown) isotope profile with a symmetrical Gaussian clock of the form $\exp \left(-0.5 z^{2} / \sigma^{2}\right)$, where the diffusion length $\sigma$ reflects the degree of smoothing and $z$ is depth. The diffusion length represents the mean vertical movement of the water molecules and this parameter is dependent on the depth, accumulation rate and temperature. The initial isotope profile can be reconstructed by performing the inverse process (deconvolution) on the measured isotope profiles. Maximum entropy method (MEM) analysis is used to calculate the power spectra of the series to estimate the $\sigma$ to be used (Fig. 5; Table 2).

The measurements of the ion concentrations of $\mathrm{Ca}^{2+}$ and $\mathrm{NH}_{4}{ }^{+}$were performed by Fuhrer and others $(1993,1996)$ by a continuous melting and continuous flow set-up. The technical resolution of the $\mathrm{NH}_{4}{ }^{+}$and $\mathrm{Ca}^{2+}$ profiles is $2 \mathrm{~mm}$, while the effective resolution is $3-4 \mathrm{~cm}$. Two methods have been applied to the raw $\mathrm{Ca}^{2+}$ data to extract as much information as possible from these data. One set has been deconvoluted to account for mixing in the apparatus during measurements. Another variant of the $\mathrm{Ca}^{2+}$ data has also been created by high-pass filtering. The long-term trends are removed, so that the high-frequency oscillations, which are of interest for annual counting, are enhanced.

The dust and $\mathrm{NO}_{3}{ }^{-}$concentrations were measured by Hammer (in press) in 1-10 mm resolution on melted ice. The effective resolution of the data is considered to be $1-4 \mathrm{~cm}$. The dust concentrations were measured by laser and calibrated by a Coulter Counter. 


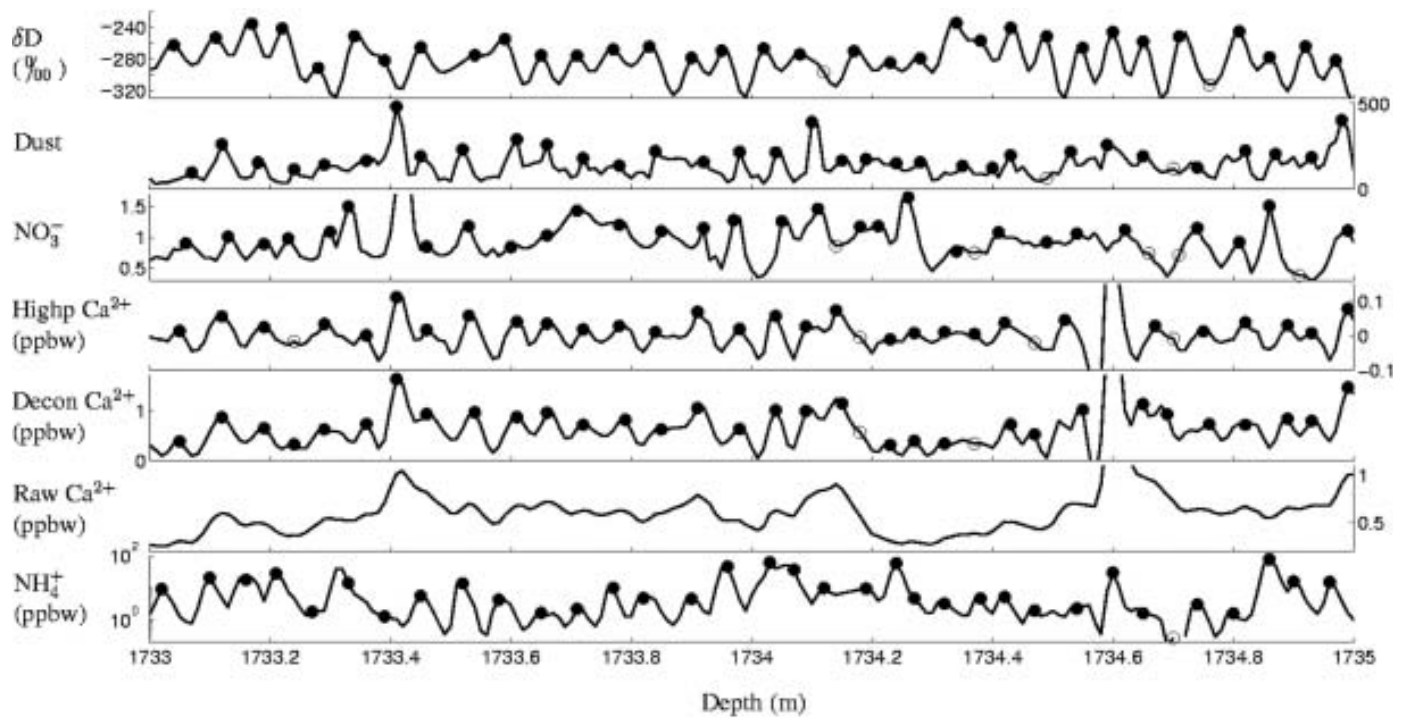

Fig. 2. Multi-parameter dating. Counting of annual layers is performed on deconvoluted $\delta \mathrm{D}$ (or $\delta^{18} \mathrm{O}$ ), dust, $\mathrm{NO}_{3}{ }^{-}, \mathrm{Ca}^{2+}$ (high-pass, deconvoluted and raw) and $\mathrm{NH}_{4}{ }^{+}$. Black dots represent certain annual layers, whereas open dots indicate uncertain annual layers. All the series are given the same amount of dots, based on a common interpretation of the cycles in the different parameters. The dots on the $\mathrm{NH}_{4}{ }^{+}$ profile constitute the 'master' series. Regarding the $\mathrm{Ca}^{2+}$ series, the dots are put on the deconvoluted and high-pass filtered data only, but the interpretation is based on all three $\mathrm{Ca}^{2+}$ variants. The units on the dust and $\mathrm{NO}_{3}{ }^{-}$profiles are arbitrary.

\section{METHOD}

The dating of the Bølling-Allerød is performed by counting annual cycles in deconvoluted $\delta \mathrm{D}$, deconvoluted $\delta^{18} \mathrm{O}$, $\mathrm{NH}_{4}{ }^{+}, \mathrm{Ca}^{2+}$ (raw, deconvoluted and high-pass filtered), dust and $\mathrm{NO}_{3}{ }^{-}$(Table 1; Fig. 2). As seen in Table 1 and Figure 1, the stable-isotope data cover less than half of the whole interval. The multi-parameter counting is done manually, with all the parameters present at one time. One 'master' series of years is established from a common interpretation of the cycles seen in all the different series. In Figure 2 this master series can be seen as dots on the $\mathrm{NH}_{4}{ }^{+}$profile. $\mathrm{A}$ 'certain year' (symbolized with a black dot) is an annual cycle that is clearly seen in all (or most) of the parameters. However, the cycles are sometimes hard to interpret (e.g. one series indicates a year where another series does not, or a possible year is seen as a shoulder on a flank of a peak). These ambiguities lead to 'uncertain years' (open dots). The best estimate is taken as the certain years + half of the uncertain years. The uncertainty is taken as half of the uncertain years. This uncertainty reflects the degree of difficulty in interpreting the available data, but does not reflect the 'true' uncertainty, as there might be a bias in the dating (e.g. if the data do not resolve all the years).

The counting was first performed on the sections where all the data were available (i.e. in the intervals where the stable isotopes have been measured), aiming at finding an overall agreement between the series. Thereafter, the rest of the Bølling-Allerød period was counted, using the experience gained from intervals containing stable-isotope profiles.

The onset of the Bølling ( $\mathrm{Gl} \mathrm{1e)} \mathrm{and} \mathrm{the} \mathrm{termination} \mathrm{of} \mathrm{the}$ Allerød (Gl 1abc) are defined based on sharp shifts seen in the deuterium-excess profile (personal communication from T. Popp, 2004) in the North Greenland Icecore Project (NorthGRIP) ice core (Dahl-Jensen and others, 2002). These depths are transferred to GRIP depth by matching profiles of electrical conductivity measurements (ECM), dielectric properties (DEP), $\mathrm{Ca}^{2+}, \mathrm{NH}_{4}{ }^{+}$(and $\delta^{18} \mathrm{O}$ ) from the two ice cores (Fuhrer and others, 1993, 1996; Taylor and others, 1993; Johnsen and others, 1997; Röthlisberger and others, 2000; Dahl-Jensen and others 2002; Bigler, 2004; NorthGRIP members, 2004). Deuterium excess, which reflects conditions in the source area for the moisture (Merlivat and Jouzel, 1979; Johnsen and others, 1989), is characterized by abrupt shifts at transitions from one climate period to another. Hence, this parameter is useful for defining the onset and terminations of the climate periods. The deuterium excess is not available from the depth of interest in the GRIP core. The transitions between the Bølling and the Older Dryas and between the Older Dryas (GI 1d) and the Allerød are defined using $\delta \mathrm{D}$ and $\delta^{18} \mathrm{O}$ in the GRIP ice core (see Table 1 for these depths). The depths of the onset of the Bølling and the termination of the Allerød differ slightly from those defined in Johnsen and others (1992), which were based on ECM, and from those defined by Hammer (in press); however, the Older Dryas depths were not stated in those papers.

Table 2. Parameters used in MEM spectral analysis. $\sigma$ is diffusion length, $m$ is autoregressive order and $f_{\max }$ is the maximum frequency allowed in the back-diffusion. The measuring error is the accuracy of the reported $\delta \mathrm{D}$ and $\delta^{18} \mathrm{O}$ values. The filter length was 100 points. The mean of each of the data series is preserved during the deconvolution process

\begin{tabular}{lllll}
\hline Interval & $\begin{array}{l}\sigma \\
\mathrm{m}\end{array}$ & $m$ & $\begin{array}{c}f_{\max } \\
\mathrm{m}^{-1}\end{array}$ & $\begin{array}{c}\text { Meas. error } \\
\% \text { \% }\end{array}$ \\
\hline$\delta \mathrm{D} \mathrm{I}$ & 0.021 & 30 & 20 & 0.9 \\
$\delta \mathrm{D} \mathrm{II}$ & 0.0215 & 30 & 19 & 0.75 \\
$\delta \mathrm{D} \mathrm{III}$ & 0.0185 & 30 & 21 & 0.55 \\
$\delta^{18} \mathrm{O}$ I & 0.023 & 40 & 19 & 0.1 \\
$\delta^{18} \mathrm{O}$ II & 0.021 & 20 & 19 & 0.085 \\
\hline
\end{tabular}



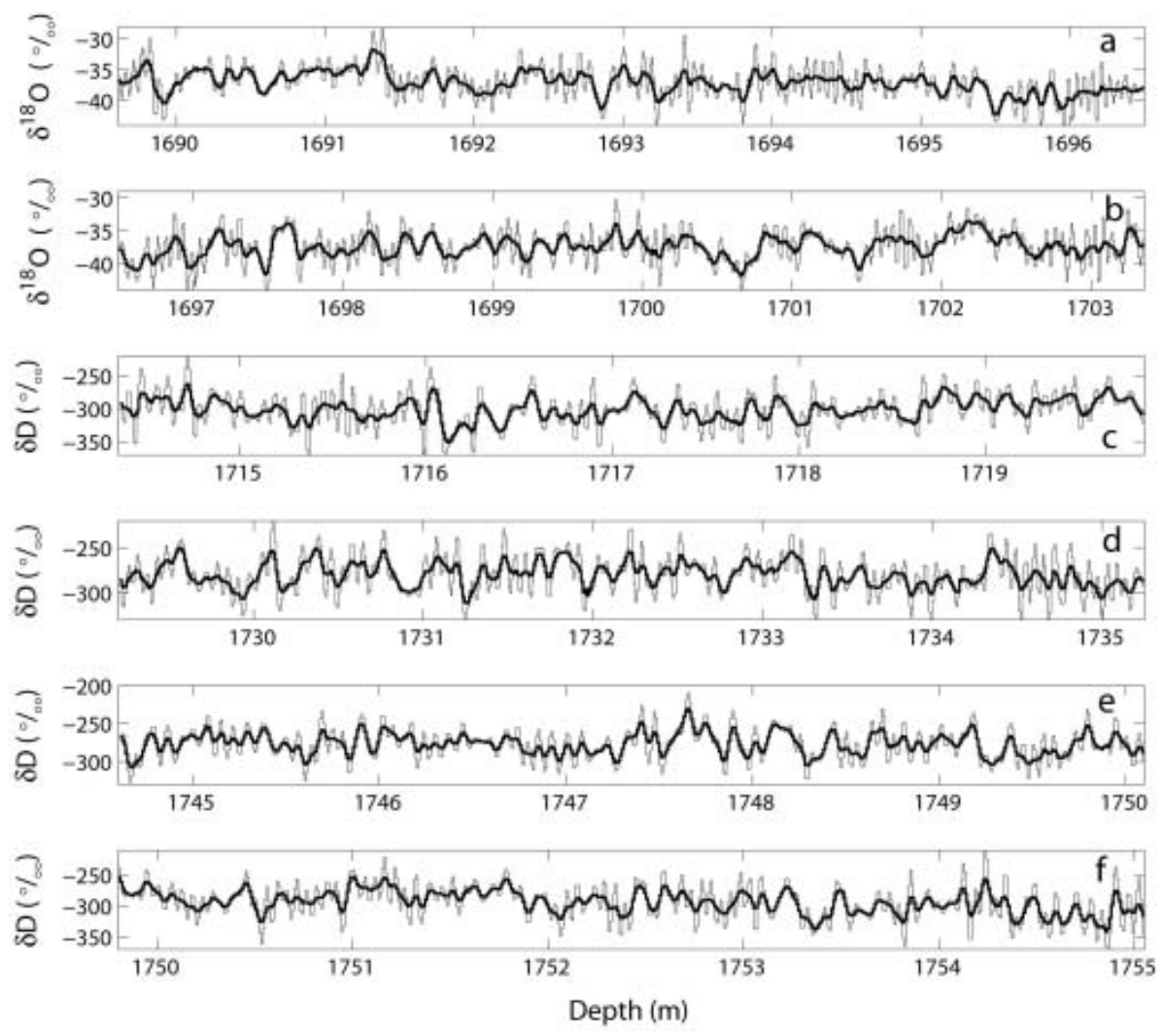

Fig. 3. Intervals of high-resolution isotope profiles from the Bølling-Allerød in the GRIP ice core. Thick lines show measured data. Thin lines show deconvoluted data where the initial isotope profile has been reconstructed (back-diffusion). The reconstructed annual signal is used for dating by counting summer peaks of high isotope values. The depth scales on the panels are different. All $\delta$ values are relative to the V-SMOW-SLAP scale. $(\mathrm{a}, \mathrm{b}) \delta^{18} \mathrm{O}$ interval I; (c) $\delta \mathrm{D}$ interval I; (d) $\delta \mathrm{D}$ interval II; and (e, f) $\delta \mathrm{D}$ interval III. See Figure 4 for $\delta^{18} \mathrm{O}$ interval II.

\section{RESULTS}

Figures 3 and 4 show all the intervals of the new highresolution stable-isotope data from the Bølling-Allerød in the GRIP ice core. The $\delta$ values are relative to the $\mathrm{V}_{-} \mathrm{SMOW}-$ SLAP scale. In Figure 3 the raw and deconvoluted data are plotted together. The intervals are labelled $\delta \mathrm{D}$ intervals I-III and $\delta^{18} \mathrm{O}$ intervals I and II, according to Table 1 . The stableisotope profiles cover a total depth of $36.85 \mathrm{~m}$, of which $1.1 \mathrm{~m}$ is an overlap between $\delta^{18} \mathrm{O}$ interval II and a part of $\delta \mathrm{D}$ interval III. This overlapping section is displayed in Figure 4a and $\mathrm{b}$, which plot the raw data and the deconvoluted data respectively. The overlapping $\delta \mathrm{D}$ and $\delta^{18} \mathrm{O}$ series are from two different cuttings of the ice and were measured separately.

Figure 5 displays the MEM power spectra for $\delta^{18} \mathrm{O}$ interval II and for the section of $\delta \mathrm{D}$ interval III that overlaps with the $\delta^{18} \mathrm{O}$ data. The spectral densities of the $\delta^{18} \mathrm{O}$ profile have been multiplied by 64 to facilitate the comparison with the spectral densities of the $\delta \mathrm{D}$ section. The power spectra of the raw data (thick lines) show how the amplitudes of high frequencies have been diminished by the diffusion in the firn and ice. The spectral densities in the high-frequency domain have been lowered, so that they are indistinguishable from the nearly flat level (white noise) that represents the measuring error (see Table 2). The arrow indicates what is considered to be the annual peaks in the power spectra. Both of the spectra for the raw data reveal an annual peak around 14-19 cycles $\mathrm{m}^{-1}$, which corresponds to a layer thickness of $5-7 \mathrm{~cm}$. The annual peak is not very pronounced and is situated close to the noise level and therefore close to the cut-off frequency. By comparing the spectra of the raw $\delta \mathrm{D}$ and $\delta^{18} \mathrm{O}$ in a band around the annual peak, it is observed that the power of $\delta \mathrm{D}$ is higher than for $\delta^{18} \mathrm{O}$, relative to that at lower frequencies. This means that the annual signal of the $\delta \mathrm{D}$ has experienced less damping than the annual signal in the $\delta^{18} \mathrm{O}$. The thin lines in Figure 5 are the power spectra of the back-diffused series. These spectra show how all the frequencies below a certain limit (determined by the cut-off frequency) are amplified to correct for the diffusion. The power density of the annual cycle, which is of interest for dating, has been increased. Table 2 lists specifications on parameters that have been used in the MEM spectral analysis and deconvolution of the stable-isotope data. The diffusion length $\sigma$ and the cut-off frequency $f_{\max }$ are used for the inverse transfer function $\exp \left(0.5 k^{2} \sigma^{2}\right)$, where $k=2 \pi f$ is the wavenumber. The choice of cut-off frequency is a best compromise between excluding the noise at higher frequencies and including the annual peak. An $f_{\max }$ of $\sim 20$ cycles $\mathrm{m}^{-1}$ seems to fulfil these conditions for the stable-isotope profiles in the BøllingAllerød. This means that back-diffused data are capable of resolving annual layers of a thickness $\geq 5 \mathrm{~cm}$. The power spectra shown in Figure 5 are typical for all the isotope intervals, although the annual peak is more blurred-out for the longer intervals such as $\delta^{18} \mathrm{O}$ interval $\mathrm{I}$ in the Allerød, where the variability in the layer thickness is likely to be higher, due to the presence of more climatic shifts.

One set of the $\mathrm{Ca}^{2+}$ data was deconvoluted to correct for mixing in the apparatus. The transfer function was $\exp (0.1 f)$, where $f$ is frequency. The cut-off frequency was 30 cycles $\mathrm{m}^{-1}$, so the data are able to resolve years of a thickness down 

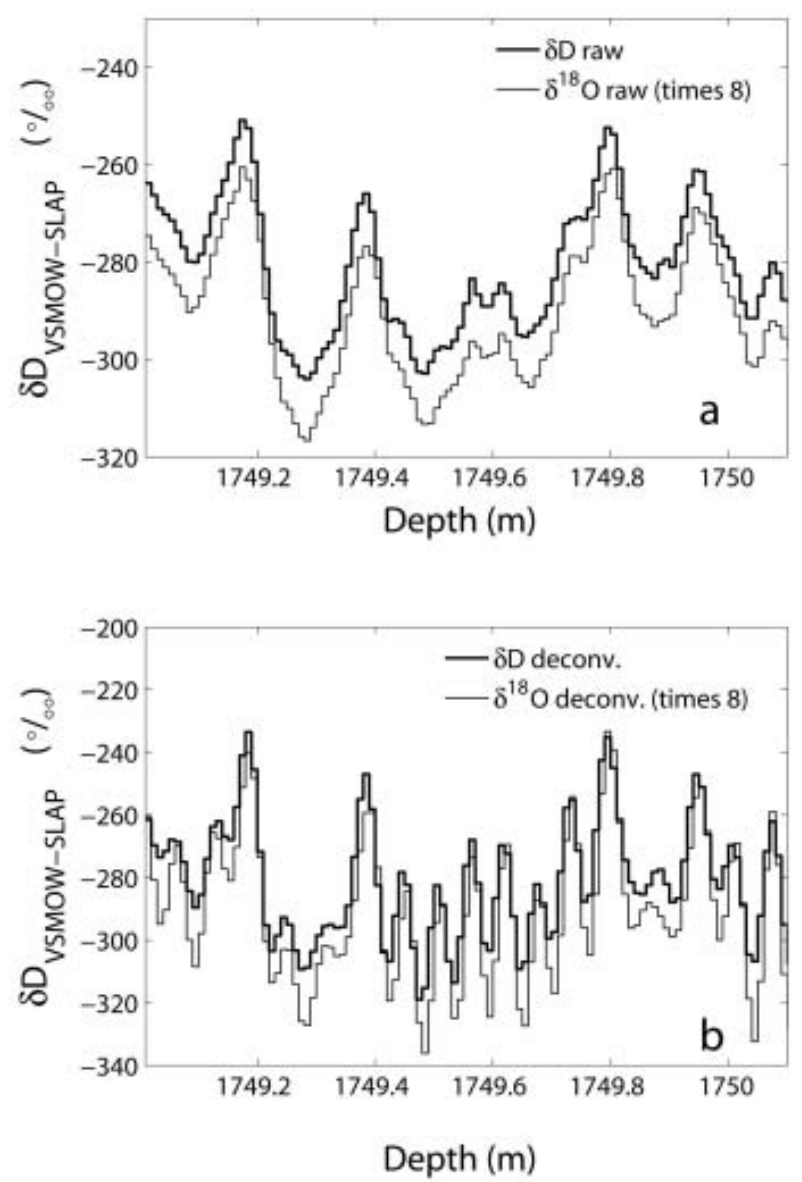

Fig. 4. $\delta \mathrm{D}$ and $\delta^{18} \mathrm{O}$ in the overlapping section in the early Bølling. (a) Raw data. (b) Back-diffused data. Thick lines show $\delta \mathrm{D}$ from part of $\delta \mathrm{D}$ interval III. Thin lines show $\delta^{18} \mathrm{O}$ interval II. The $\delta^{18} \mathrm{O}$ values are multiplied by 8 . There is good agreement between the two different isotope profiles, which were measured separately on different cuttings of the ice.

to $3.3 \mathrm{~cm}$. It should be mentioned that the deconvolution corrects only the amplitudes of the cycles, not their relative phases. Another set of $\mathrm{Ca}^{2+}$ was filtered through a smooth Gaussian high-pass filter.

Looking at the seasonal cycles in all the parameters (e.g. Fig. 2), there is an overall agreement between the parameters. $\mathrm{NO}_{3}{ }^{-}$is the parameter that deviates most, generally showing fewer cycles than the other parameters. However, in some periods $\mathrm{NO}_{3}{ }^{-}$agrees well with the other parameters. The dust profile often has more peaks than the other parameters. Under present-day conditions, $\mathrm{NH}_{4}{ }^{+}$and $\mathrm{NO}_{3}{ }^{-}$ have maxima during summer, like $\delta \mathrm{D}$ and $\delta^{18} \mathrm{O}$, while dust and $\mathrm{Ca}^{2+}$ normally peak during spring. This is also the main feature during the Bølling-Allerød, though there are periods when this is not the case. The parameters are often out of their usual phasing, especially in the Allerød. Hence, the seasonality pattern seems to have had a higher variability than for present-day conditions.

The depth scales of dust and $\mathrm{NO}_{3}{ }^{-}$, which were measured simultaneously, have been shifted a few places within the investigation interval. This is done because of indications of holes in the data or discrepancies in the depth of characteristic peaks observed in both $\mathrm{Ca}^{2+}$ and dust. The adjustment of the depth scales was aimed at synchronizing these distinct peaks, under the assumption that characteristic peaks in $\mathrm{Ca}^{2+}$ and dust reflect the same deposition events.

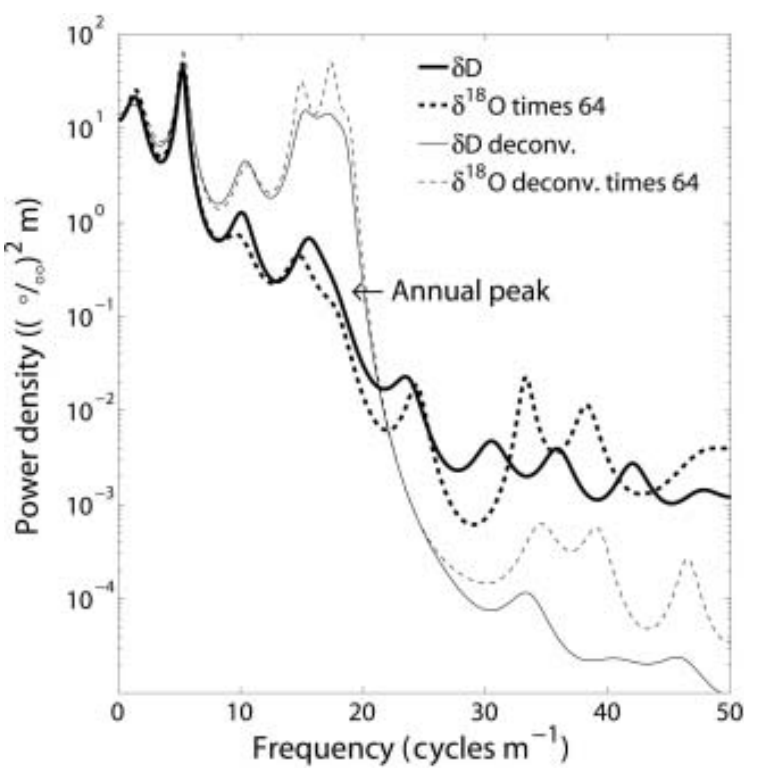

Fig. 5. MEM spectral densities for $\delta^{18} \mathrm{O}$ interval II (dotted lines) and part of $\delta \mathrm{D}$ interval III (solid lines) in the overlapping section in the early Bølling (see Fig. 4). Thick lines show raw data. Thin lines show back-diffused data. Autoregressive order $m$ is $20, f_{\max }$ is 19 and $\sigma$ is $0.0185 \mathrm{~m}(\delta \mathrm{D})$ and $0.021 \mathrm{~m}\left(\delta^{18} \mathrm{O}\right)$. The annual peak is seen around 14-19 cycles $\mathrm{m}^{-1}$, which equals an annual-layer thickness of 5-7 cm. The spectral densities of $\delta^{18} \mathrm{O}$ are multiplied by 64 to make the comparison with the spectral densities of $\delta \mathrm{D}$ easier. For wavenumbers around the annual peak, the damping is smaller for $\delta \mathrm{D}$ than for $\delta^{18} \mathrm{O}$.

The range of shift was between -70 and $+50 \mathrm{~mm}$, where the latter amount of displacement was the most common.

The annual-layer counting based on seasonal variations in $\delta \mathrm{D}, \delta^{18} \mathrm{O}, \mathrm{NH}_{4}{ }^{+}, \mathrm{Ca}^{2+}$ dust and $\mathrm{NO}_{3}{ }^{-}$gives estimated lengths of $588 \pm 16$ years for the Bølling, $70 \pm 4$ years for the Older Dryas and $971 \pm 31$ years for the Allerød. The uncertainty reflects the inconsistency between the series and the difficulty of interpreting the peaks and shoulders. The uncertainty does not take into account any bias in the counting. The corresponding mean annual-layer thicknesses of the three periods are 5.9, 5.1 and $5.4 \mathrm{~cm}$ respectively.

\section{DISCUSSION}

The counting method is based on a common interpretation of all the data series, first in the intervals containing stable isotopes and then in the rest of the Bølling-Allerød period. The result is highly dependent on the resolution and the internal consistency of the data series. The dust profile generally has more peaks than the other parameters, favouring the highest number of years, while the stable isotopes and the $\mathrm{NO}_{3}{ }^{-}$generally put a lower limit on the number. The $\mathrm{Ca}^{2+}$ and $\mathrm{NH}_{4}^{+}$generally serve as good dating tools. The effective resolution of these profiles is $3-4 \mathrm{~cm}$, so they can resolve cycles up to this wavelength. As previously mentioned, dust can have more than one peak within some years. The exclusion of dust peaks which are considered as 'double peaks' has been decided by comparison with the seasonal cycles in the stable isotopes, $\mathrm{Ca}^{2+}, \mathrm{NH}_{4}{ }^{+}$and $\mathrm{NO}_{3}{ }^{-}$. Hence, it is crucial that these parameters can resolve all the years. Within certain periods this is definitely not the case for $\mathrm{NO}_{3}{ }^{-}$, because the profile is too smooth. Within these intervals, no weight has been put on the $\mathrm{NO}_{3}{ }^{-}$in the 
Table 3. Estimates of the duration of the Bølling (B), Older Dryas (OD) and Allerød (A) from Greenland ice cores. The GISP2 ice core (Grootes and others, 1993) is situated $28 \mathrm{~km}$ west of GRIP, and the NorthGRIP ice core (Dahl-Jensen and others, 2002) is located $325 \mathrm{~km}$ northwest of GRIP

\begin{tabular}{llccc}
\hline Core & Method & $\begin{array}{c}\mathrm{B} \\
\text { years }\end{array}$ & $\begin{array}{c}\text { OD } \\
\text { years }\end{array}$ & $\begin{array}{c}\mathrm{A} \\
\text { years }\end{array}$ \\
\hline GRIP & $\mathrm{Ca}^{2+}, \mathrm{NH}_{4}^{+}$, dust, & $588 \pm 16$ & $70 \pm 4$ & $971 \pm 31$ \\
& $\delta \mathrm{D}, \delta^{18} \mathrm{O}_{3}{ }^{-}$ & & & \\
GRIP & Dust $^{*}$ & 736 & & 1432 \\
GRIP & Modelled (ss09sea) $^{\dagger}$ & 643 & 92 & 1167 \\
GISP2 & Ice layer count $^{*}$ & 580 & 80 & 1120 \\
NorthGRIP & $\begin{array}{l}\text { Continuous flow } \\
\text { analysis data }\end{array}$ & $615 \pm 17$ & $92 \pm 3$ & $1087 \pm 28$ \\
& & & & \\
\hline
\end{tabular}

\section{*Hammer (in press).}

tohnsen and others (2001)

"Stuiver and others (1995); Alley and others (1997); Meese and others (1997).

${ }^{\text {S}}$ Rasmussen and others 2006

Notes: The Older Dryas was not specified in Hammer (in press). Their depths used for defining the Bølling and the Allerød are 1572.85, 1718.20 and $1662.65 \mathrm{~m}$. The GISP2 dating uncertainty is $5 \%$ (Alley and others, 1993). Depths used in the GISP2 dating for defining the periods have not been accurately transferred to the GRIP scale, but comparison of the $\delta^{18} \mathrm{O}$ profiles from GRIP (Johnsen and others, 1997) and GISP2 (Stuiver and others, 1995; The Greenland Summit Ice Cores CD-ROM, 1997) shows that any deviation of the definitions of the onsets and terminations is insignificant compared to the uncertainty in dating.

interpretation. When it comes to $\delta \mathrm{D}$ and $\delta^{18} \mathrm{O}$, it is evident that the annual cycles are present in the stable-isotope profiles from this interstadial. The power spectra reveal a peak around $14-19$ cycles $\mathrm{m}^{-1}$ for both $\delta \mathrm{D}$ and $\delta^{18} \mathrm{O}$, which indicates that there is power left in the annual signal in both of the stable-isotope series, and that they can be used for dating purposes. That this peak reflects a true seasonal signal is confirmed by the good agreement between $\delta \mathrm{D}$ and $\delta^{18} \mathrm{O}$ in the overlapping section in Figure 4. If the peaks in the spectral densities represented noise only, it would not be possible to create such a compelling agreement between the back-diffused $\delta \mathrm{D}$ and $\delta^{18} \mathrm{O}$ data, as the noise in the two profiles is uncorrelated. Hence, it is unquestionable that there is power left in the annual amplitude of the stableisotope profiles. What remains to be answered is whether all the years are resolved. The method of using stable isotopes for dating is certainly at the limit at this depth, where the ice is $14-15 \mathrm{kyr}$ old. The MEM power spectra of the raw data show that there is little power left in the annual cycle and that the annual peak is close to the noise level. This indicates that some years of low accumulation (high frequency) may not have been revealed by the deconvolution, as they are hidden in the noise and thereby ruled out by the cut-off frequency. With a cut-off frequency of $\sim 20$ cycles $\mathrm{m}^{-1}$, annual layers less than $\sim 5 \mathrm{~cm}$ thick will not be resolved. This is supported by the fact that shoulders are seen on flanks of $\delta$ peaks when other parameters have peaks (or clear shoulders). If some years are lost in the stable-isotope profiles, this will lead to a too low estimation of the duration of the periods.

In the section where the $\delta \mathrm{D}$ and the $\delta^{18} \mathrm{O}$ profiles overlap, it is observed that the damping of the signal is stronger for $\delta^{18} \mathrm{O}$ than for $\delta \mathrm{D}$. This is due to less diffusion of molecules containing ${ }^{2} \mathrm{H}$ compared to molecules containing
${ }^{18} \mathrm{O}$ and is in accordance with earlier results and theory (Johnsen and others, 2000). The lower damping of the $\delta \mathrm{D}$ signal suggests that $\delta \mathrm{D}$ is slightly better for dating when working with ice where the amplitude of the annual signal of the stable isotopes is close to the limit of detection.

According to data from Dahl-Jensen and others (1993), the mean accumulation rate (based on $\delta^{18} \mathrm{O}$ ) at GRIP during the Bølling was $0.23 \pm 0.02 \mathrm{~m} \mathrm{a}^{-1}$, while it was $0.15 \pm 0.02 \mathrm{~m} \mathrm{a}^{-1}$ during the Older Dryas and $0.18 \pm 0.02 \mathrm{~m} \mathrm{a}^{-1}$ during the Allerød. As $0.20 \mathrm{~m} \mathrm{a}^{-1}$ is considered as the minimum accumulation rate under present-day conditions for the annual cycle to survive (Johnsen, 1977), it is interesting that it is possible to detect the annual amplitude within the stableisotope series from the Older Dryas and the Allerød. This can be explained either by higher accumulation rates than those derived from $\delta^{18} \mathrm{O}$, or by lower temperatures than at present. $\delta^{18} \mathrm{O}$-derived paleotemperatures (Johnsen and others, 1995) from the GRIP ice core show that it was only $1^{\circ} \mathrm{C}$ colder during the Bølling than today, while it was $5-12^{\circ} \mathrm{C}$ colder during the Older Dryas and the Allerød. Lower temperatures may have slowed down the process of diffusion in the firn and ice.

Compared to the Bølling interval, the data in the Older Dryas and the Allerød are more difficult to interpret. The seasonal variability is higher, the parameters are often out of phase and the agreement between the data is less compelling. The mean annual-layer thickness in the Bølling agrees well with the value found by Dahl-Jensen and others (1993), of $5.8 \pm 0.6 \mathrm{~cm}$. However, the mean annual-layer thicknesses within the Older Dryas and the Allerød are greater than those found by Dahl-Jensen and others (1993). They estimate a mean annual-layer thickness of $4.0 \pm 0.3 \mathrm{~cm}$ and $4.9 \pm 0.7 \mathrm{~cm}$ in the Older Dryas and the Allerød, respectively, with minima of $3-3.5 \mathrm{~cm}$. This could indicate that some of the annual layers within the Older Dryas and the Allerød are too thin to be resolved properly by the data used in the multi-parameter dating.

Table 3 displays other estimates of the duration of the Bølling, Older Dryas and Allerød periods in Greenland ice cores. Compared with the previous stratigraphical dating on the GRIP ice core (Hammer, in press), the number of years is substantially lower for the multi-parameter approach. The Older Dryas was not specified in the work by Hammer, and the definitions of the onset and terminations differed slightly from those used in this study (see Tables 1 and 3). Using the depths from Hammer (in press), the corresponding estimates for the multi-parameter approach are $585 \pm 17$ years for the Bølling and $1028 \pm 34$ years for the Allerød. These estimates are $\sim 20 \%$ and $\sim 30 \%$ shorter than those found by Hammer. This huge deviation can be explained by different approaches to the layer counting. The dating accomplished by using dust concentrations only, without guidance from other parameters, may have overestimated the number of years, by including too many 'double peaks'. On the other hand, the method used in this study may have underestimated the duration of the climate periods, as the 'restricting' data cannot resolve annual layers of low thickness, especially in colder parts of the periods, where the accumulation rates have been lower. Compared to the modelled timescale ss09sea (Johnsen and others, 2001), which is based on a Dansgaard-Johnsen flow model and $\delta^{18} \mathrm{O}$-derived accumulation rates, the new estimates from the multi-parameter counting are $\sim 9 \%, \sim 24 \%$ and $\sim 17 \%$ shorter, for the Bølling, Older Dryas and Allerød, respectively. 
The estimated length of the Bølling agrees well with the number of years found by annual-layer counting of the Greenland Ice Sheet Project 2 (GISP2) ice core (Alley and others, 1993, 1997; Stuiver and others, 1995; Meese and others, 1997). The estimated durations of the Older Dryas and the Allerød are $~ 13 \%$ shorter than those from the GISP2 layer counting.

The NorthGRIP ice core (Dahl-Jensen and others, 2002; NorthGRIP members, 2004) is currently being dated by the members of the NorthGRIP dating group (e.g. Rasmussen, 2006; Vinther, in press). The stratigraphical dating of this core is made by identification and counting of annual cycles as observed in chemical components measured in a continuous flow system (Röthlisberger and others, 2000; Bigler, 2004). Compared with new results from the dating of the NorthGRIP core (Rasmussen and others, 2006), the present estimate of the duration of the Bølling is within $2 \sigma$ of the estimate of the length of the Bølling in the NorthGRIP core. The estimated durations of the Older Dryas and the Allerød are $\sim 25 \%$ and $\sim 11 \%$ shorter than those from the dating of the NorthGRIP core.

To summarize, the durations of the Bølling-Allerød estimated by multi-parameter layer counting in the GRIP ice core are generally shorter than other estimates from ice cores in the same region. The estimate of the Bølling period agrees well with GISP2 annual-layer counting and with the results from the NorthGRIP stratigraphical dating, while estimates of the Older Dryas and the Allerød are significantly shorter than in the other datings listed in Table 3. This indicates that the data used in the multi-parameter approach in the GRIP core can resolve annual layers in the relatively warm Bølling, while some years may have been lost in the colder Older Dryas and Allerød.

\section{CONCLUSION}

Multi-parameter counting has been accomplished in the Bølling-Allerød period (Greenland Interstadial 1) in the GRIP ice core, by using the parameters $\mathrm{Ca}^{2+}, \mathrm{NH}_{4}{ }^{+}$, dust, $\mathrm{NO}_{3}{ }^{-}$and new stable-isotope profiles showing seasonal variations.

New high-resolution data presented in this study show that it is possible to use stable isotopes for stratigraphical dating of glacial ice from Greenland Interstadial 1. The annual cycle is seen in MEM power spectra, and the cycles of the stable isotopes compare well with the annual cycles in the chemical data series and the seasonal variations in dust concentrations. It is, however, necessary to deconvolute the measured isotope profiles to reconstruct the initial isotope signals. By this method the annual cycles are amplified and easier to interpret. The maximum resolution of the deconvoluted stable-isotope data from the Bølling-Allerød is $\sim 5 \mathrm{~cm}$, so thinner annual layers will not be resolved by these data. This implies that some years are lost in colder periods having lower accumulation rates, especially within the Older Dryas and Allerød periods. Furthermore, this study confirms the findings of Johnsen and others (2001) that the damping of the annual amplitude, due to diffusion in the firn and ice, is stronger for $\delta^{18} \mathrm{O}$ than for $\delta \mathrm{D}$. This suggests that $\delta \mathrm{D}$ is better suited for dating than $\delta^{18} \mathrm{O}$ when working on ice where the annual signal in the data is weak.

That the annual amplitudes in the $\delta \mathrm{D}$ and $\delta^{18} \mathrm{O}$ profiles are detectable suggests that the annual accumulation rate during the Bølling-Allerød period was at least (or close to)
$0.20 \mathrm{~m}$ ice $\mathrm{a}^{-1}$. With a lower accumulation rate, the annual signal would be less likely to survive the diffusion processes in the firn and ice (Johnsen, 1977).

The estimated durations of the Bølling (Gl 1e), Older Dryas (Gl 1d) and Allerød (GI 1abc) periods based on the multi-parameter layer counting in the GRIP ice core are $588 \pm 16,70 \pm 4$ and $971 \pm 31$ years, respectively. The uncertainties reflect difficulties in interpreting the available data and do not take into account any bias in the dating. The estimates are considered as lower limits for these climate periods, as some years may not have been resolved by the data in colder periods with lower accumulation, especially within the Older Dryas and the Allerød.

This study underlines the importance of having highresolution data when performing stratigraphical dating of ice cores, and having a variety of independent parameters showing seasonal variations.

\section{ACKNOWLEDGEMENTS}

We are indebted to $\mathrm{V}$. Pohjola and an anonymous reviewer for helpful review, as well as the scientific editor, E. Isaksson, for fruitful comments. We also thank T. Ebbensgaard Strømfeldt, T. Jürgensen and A. Boas for providing the high-resolution $\delta^{18} \mathrm{O}$ data, S.O. Rasmussen for providing the program Datetool, the Copenhagen Ice Core Dating Initiative (funded by the Carlsberg Foundation), and the Glaciology Group at the Niels Bohr Institute, University of Copenhagen. The staff at the $\mathrm{AMC}{ }^{14} \mathrm{C}$ Dating Centre, Department of Physics and Astronomy, University of Århus, are also thanked for helpful assistance during the $\delta \mathrm{D}$ analysis.

\section{REFERENCES}

Alley, R.B. and 10 others. 1993. Abrupt increase in Greenland snow accumulation at the end of the Younger Dryas event. Nature, 362(6420), 527-529.

Alley, R.B. and 11 others. 1997. Visual-stratigraphic dating of the GISP2 ice core: basis, reproducibility, and application. J. Geophys. Res., 102(C12), 26,367-26,382.

Bigler, M. 2004. Hochauflösende Spurenstoffmessungen an polaren Eisbohrkernen: Glazio-chemische und klimatische Prozessstudien. (PhD thesis, University of Bern.)

Coplen, T.B. 1988. Normalization of oxygen and hydrogen isotope data. Chemical Geol. (Isotope Geoscience Section), 72, 293-297.

Dahl-Jensen, D., S.J. Johnsen, C.U. Hammer, H.B. Clausen and J. Jouzel. 1993. Past accumulation rates derived from observed annual layers in the GRIP ice core from Summit, central Greenland. In Peltier, W.R., ed. Ice in the climate system. Berlin, etc., Springer-Verlag, 517-532. (NATO ASI Series I: Global Environmental Change 12.)

Dahl-Jensen, D. and 8 others. 2002. The NorthGRIP deep drilling programme. Ann. Glaciol., 35, 1-4.

Fuhrer, K., A. Neftel, M. Anklin and V. Maggi. 1993. Continuous measurements of hydrogen peroxide, formaldehyde, calcium and ammonium concentrations along the new GRIP ice core from Summit, central Greenland. Atmos. Environ., A27(12), 1873-1880.

Fuhrer, K., A. Neftel, M. Anklin, T. Staffelbach and M. Legrand. 1996. High-resolution ammonium ice core record covering a complete glacial-interglacial cycle. J. Geophys. Res., 101(D2), 4147-4164. 
Greenland Ice-Core Project (GRIP) Members. 1993. Climate instability during the last interglacial period recorded in the GRIP ice core. Nature, 364(6434), 203-207.

The Greenland Summit Ice Cores CD-ROM. 1997. Available from the National Snow and Ice Data Center, University of Colorado at Boulder, and the World Data Center-A for Paleoclimatology, National Geophysical Data Center, Boulder, Colorado.

Grootes, P.M., M. Stuiver, J.W.C. White, S. Johnsen and J. Jouzel. 1993. Comparison of oxygen isotope records from the GISP2 and GRIP Greenland ice cores. Nature, 366(6455), 552-554.

Hammer, C.U. In press. Ice core chronology. In Knight, P., ed. Glacier science and environmental change. Oxford, Blackwell Publishing.

IUPAC [International Union of Pure and Applied Chemistry] Commission on Atomic Weights and Isotopic Abundances. 1994. Atomic weights of the elements 1993. Pure Appl. Chem., 66(12), 2423-2444.

Johnsen, S.J. 1977. Stable isotope homogenization of polar firn and ice. In Isotopes and Impurities in Snow and Ice. Wallingford, Oxon., International Association of Hydrological Sciences, 210219. (IAHS Publication 118.)

Johnsen, S.J., W. Dansgaard and J.W.C. White. 1989. The origin of Arctic precipitation under present and glacial conditions. Tellus, 41B $(4)$, 452-468.

Johnsen, S.J. and 9 others. 1992. Irregular glacial interstadials recorded in a new Greenland ice core. Nature, 359(6393), 311-313.

Johnsen, S.J., D. Dahl-Jensen, W. Dansgaard and N.S. Gundestrup. 1995. Greenland paleotemperatures derived from GRIP borehole temperature and ice core isotope profiles. Tellus, 47B(5), 624-629.

Johnsen, S.J. and 14 others. 1997. The $\delta^{18} \mathrm{O}$ record along the Greenland Ice Core Project deep ice core and the problem of possible Eemian climatic instability. J. Geophys. Res., 102(C12), 26,397-26,410.

Johnsen, S.J., H.B. Clausen, J. Jouzel, J. Schwander, A.E. Sveinbjörnsdóttir and J. White. 1999. Stable isotope records from Greenland deep ice cores. In Wettlaufer, J.S., J.G. Dash and N. Untersteiner, eds. Ice physics and the natural environment. Berlin, etc., Springer-Verlag, 89-107. (NATO ASI Series I: Global Environmental Change 56.)
Johnsen, S.J., H.B. Clausen, K.M. Cuffey, G. Hoffmann, J. Schwander and T. Creyts. 2000. Diffusion of stable isotopes in polar firn and ice: the isotope effect in firn diffusion. In Hondoh, T., ed. Physics of ice core records. Sapporo, Hokkaido University Press, 121-140.

Johnsen, S.J. and 8 others. 2001. Oxygen isotope and palaeotemperature records from six Greenland ice-core stations: Camp Century, Dye-3, GRIP, GISP2, Renland and NorthGRIP. J. Quat. Sci., 16(4), 299-307.

Meese, D.A. and 8 others. 1997. The Greenland Ice Sheet Project 2 depth-age scale: methods and results. J. Geophys. Res., 102(C12), 26,411-26,423.

Merlivat, L. and J. Jouzel. 1979. Global climatic interpretation of the deuterium-oxygen 18 relationship for precipitation. J. Geophys. Res., 84(C8), 5,029-5,033.

Morrison, J., T. Brockwell, T. Merren, F. Fourel and A.M. Phillips. 2001. On-line high-precision stable hydrogen isotopic analyses on nanoliter water samples. Anal. Chem., 73(15), 3570-3575.

Nelson, S.T. 2000. A simple, practical methodology for routine VSMOW/SLAP normalization of water samples analyzed by continuous flow methods. Rapid Commun. Mass. Sp., 14, 1044-1046.

North Greenland Ice Core Project members. 2004. High-resolution record of Northern Hemisphere climate extending into the last interglacial period. Nature, 431(7005), 147-151.

Rasmussen S.O. and 15 others. 2006. A new Greenland ice core chronology for the last glacial termination. J. Geophys. Res. 111(D6) (10.1029/2005JD006079.)

Röthlisberger, R. and 6 others. 2000. Technique for continuous high-resolution analysis of trace substances in firn and ice cores. Envir. Sci. Technol., 34(2), 338-342.

Stuiver, M., P.M. Grootes and T.F. Braziunas. 1995. The GISP2 $\delta^{18} \mathrm{O}$ climate record of the past 16,500 years and the role of the Sun, ocean and volcanoes. Quat. Res., 44(3), 341-354.

Taylor, K.C. and 9 others. 1993. Electrical conductivity measurements from the GISP2 and GRIP Greenland ice cores. Nature, 366(6455), 549-552.

Vinther B.M. and 12 others. In press. A synchronized dating of three Greenland ice cores throughout the Holocene. J. Geophys. Res. (10.1029/2005JD006921.) 